\title{
In Vivo Study for Anti-inflammatory Activity of Bauhinia variegata L. Leaves
}

\author{
Santanu Saha ${ }^{\mathrm{a}, *}$, E.V.S. Subrahmanyam ${ }^{\mathrm{b}}$, K.S. Chandrashekar ${ }^{\mathrm{c}}$ and Shashidhara C. Shastry ${ }^{\mathrm{d}}$
}

${ }^{a}$ Department of Pharmacognosy, NGSM Institute of Pharmaceutical Sciences, Nitte University, Paneer, Derelakatte, Mangalore 575018, Karnataka, India; ${ }^{b}$ Department of Pharmaceutical Chemistry, Srinivas College of Pharmacy, Vallachil, Mangalore 574 143, Karnataka, India; ${ }^{c}$ Department of Pharmacognosy, Manipal College of Pharmaceutical Sciences, Manipal University, Manipal 576 104, Karnataka, India; ${ }^{d}$ Principal, NGSM Institute of Pharmaceutical Sciences, Nitte University, Paneer, Derelakatte, Mangalore 575018, Karnataka, India.

\begin{abstract}
Bauhinia variegata L. (Rakta kanchan) has been traditionally used in India for treatment of a variety of inflammatory conditions, skin diseases, stomatitis, leprosy and for wound healing. Using mostly in vitro models, a number of published reports confirmed the anti-inflammatory potential of the leaves, bark and roots of this tree. The isolation of a bioactive triterpene saponin from the leaves and a flavonol glycoside from the roots has also been reported. In the present study, we have evaluated the anti-inflammatory activity of the leaf extract of B. variegata, using three in vivo animal models: the carrageenan induced rat paw edema, cotton pellets induced granuloma formation, and adjuvant induced arthritis in rat. Both the ethanol extract and the petroleum ether fraction obtained from this extract demonstrated activity in all the three bioassays. The activity was found to be more pronounced in the petroleum ether fraction. These bioactivities compared favorably with diclofenac sodium, which was used as positive control, and confirms the traditional usefulness of this plant for the treatment of both acute and chronic inflammatory conditions.
\end{abstract}

Keywords: Adjuvant-induced arthritis, Anti-inflammatory activity, Bauhinia variegata, Fabaceae, Cotton pellet granuloma, Ethanol extract, Petroleum ether fraction.

\section{INTRODUCTION}

India is one of the largest producers of medicinal herbs in the world [1]. The Indian traditional healthcare system, Ayurveda provides relatively organized database and more exhaustive description of botanical materials, many of which have been used as templates for novel drug development [2]. Bauhinia variegata L. (Fabaceae), commonly known as 'Rakta kanchan' is distributed in sub-Himalayan and outer Himalaya of the Punjab and Sikkim. It is also found in Burma and China. Traditionally, various parts of this plant are used as anthelmintic, astringent, anti-leprotic, liver tonic, antibacterial and in the treatment of dysmenorrhoea. According to different indigenous medicinal systems of India, the plant is also useful for treatment of skin diseases, wounds, edema, dysentery, ulcers, eye disease, piles, hemorrhoids and snake bite [3-7]. The various biological activities such as antimicrobial, anti-inflammatory, antitumor, cytotoxic and hepatoprotective activities of this plant have also been reported [8-12]. Earlier studies on leaves of B. variegata reported the isolation of insulin like protein, an antiinflammatory triterpenoid saponin and flavonoids. In the present study, we further corroborated the anti-inflammatory activity of the ethanolic extract and petroleum ether-soluble fraction of this extract using in vivo models for acute and chronic inflammation.

\footnotetext{
*Address correspondence to this author at the Department of Pharmacognosy, NGSM Institute of Pharmaceutical Sciences, Nitte University, Paneer, Derelakatte, Mangalore 575018, Karnataka, India; Tel: +91 824 2203991; Fax: +91 824 2203992;

E-mail: saha.santanu@rediffmail.com
}

\section{MATERIALS AND METHODS}

\section{Chemicals}

All the chemicals and reagents used were obtained in high purity either from S.D. fine chemicals Pvt. Ltd; Bombay, India or E. Merck (India) Ltd., Mumbai. Carrageenan (Hi-Media Research Laboratories Pvt. Ltd., Mumbai), Tween80 (S.D. fine Chemicals Pvt. Ltd., Mumbai), Complete Freund's Adjuvant (FCA) (Sigma Aldrich St. Louis, USA) and Diclofenac sodium (Diclo) was a gift from M/S Jagsonpal, New Delhi.

\section{Plant Material}

The leaves of $B$. variegata were collected from Paneer, India during August 2008. A voucher specimen (voucher no. 324 b) was deposited in NGSM Institute of Pharmaceutical Sciences, Derelakatte, Mangalore, India.

\section{Extraction}

The shade dried powdered leaves $(5 \mathrm{~kg})$ were exhaustively extracted with $95 \%$ ethanol, and the solvent removed by evaporation on a water bath to give $400 \mathrm{~g}$ of extract (BVE). A non-polar fraction was obtained by partitioning the ethanol extract $(400 \mathrm{~g})$ between petroleum ether $\left(60-80^{\circ} \mathrm{C}\right)$ and water to give $40 \mathrm{~g}$ petroleum ether-soluble (BVPT).

\section{Animals and Study Groups}

Studies were carried out using Albino Wistar rats weighing $180-200 \mathrm{~g}$ of either sex. Animals were obtained from 
K.S. Hegde Medical Academy (KSHEMA), Deralakatte, Mangalore, and housed in polyacrylic cages (6 animals per cage), for one week at standard laboratory conditions $\left[\left(25^{\circ} \mathrm{C}\right.\right.$ $\pm 2^{\circ} \mathrm{C}$ ), relative humidity $60 \pm 5 \%$ and $12 \mathrm{~h}$ light and dark cycle]. The diet was standard pellets (Hindustan Lever Limited, Mumbai, India) and water was given ad libitum. One group served as negative control receiving orally $3 \mathrm{~mL}$ of $1 \%$ Tween 80 each. Another group, the positive control, was given $13.5 \mathrm{mg} / \mathrm{kg}$ Diclofenac sodium orally [13]. The study groups $(n=6)$ received orally $100,200,400 \mathrm{mg} / \mathrm{kg}$ each of freshly prepared suspension (in 1\% Tween 80 ) of either BVE or BVPT.

The study protocols were approved by Institutional Animal Ethical Committee (KSHEMA /AEC/077/2008).

\section{Acute Toxicity Study}

Acute toxicity study was conducted to determine the median lethal dose $\left(\mathrm{LD}_{50}\right)$ of the two extracts, BVE and BVPT, in adult female albino Wistar rats following OECD guideline no. 425 [14]. Animals were administered the extract preparations orally, and observed at half hour intervals for $4 \mathrm{~h}$, then after $24 \mathrm{~h}$. Both extracts were found to be safe up to an oral dose of $2000 \mathrm{mg} / \mathrm{kg}$.

\section{In Vivo Anti-inflammatory Studies}

\section{Carrageenan Induced Rat Paw Edema}

The carrageenan induced rat paw edema was carried out as described by Winter et al. [15] to evaluate acute antiinflammatory activity of BVE and BVPT. Paw edema was induced by injecting $0.1 \mathrm{~mL}$ of $1 \%(\mathrm{w} / \mathrm{v})$ carrageenan suspension in $0.9 \%(\mathrm{w} / \mathrm{v})$ sterile saline into the plantar tissue of the left hind paw of all animals, one hour following oral administration of either control vehicle, Diclofenac sodium or plant extracts. The right paw served as reference to measure the degree of inflammation in the left one. Increase in paw volume was measured at four hourly intervals, following carrageenan injection, using a plethysmograph [16]. The percentage inhibition of inflammation, calculated as inhibition of edema volume, was calculated [17] as follows:

Percentage Inhibition of Inflammation $=\left(1-V_{t} / V_{c}\right) \mathrm{X} 100$

$\mathrm{V}_{\mathrm{t}}$ is the average paw edema volume of each extract treated group, as well as Diclofenac sodium group;

$\mathrm{V}_{\mathrm{c}}$ is the paw volume of the negative control group that only received the vehicle.

\section{Cotton Pellets Induced Granuloma in Rats}

The granuloma in albino Wistar rats was induced by implanting cotton pellets [18]. All animals were anaesthetized with ether after shaving the fur, and $10 \mathrm{mg}$ of sterile cotton pellets were inserted, one in each axilla. The extracts, control vehicle and Diclofenac sodium were administered orally every day for 7 days. On the eighth day, the animals were anaesthetized and the cotton pellets surgically removed and cleaned from extraneous tissues. The moist pellets were weighed, dried at $60^{\circ} \mathrm{C}$ for $24 \mathrm{~h}$ and then re-weighed. Increment in dry weight of pellets was taken as measure of granuloma formation.

\section{Adjuvant Induced Arthritis in Rats}

Arthritis was induced by the injection of $0.1 \mathrm{~mL}$ of FCA, (containing $1 \mathrm{mg} / \mathrm{mL}$ of heat killed Mycobacterium tuberculosis in paraffin oil and mannide monooleate) into the subplantar region of right hind paw of rat. Two hours prior to the injection, each group of animals received the assigned treatment, which was then continued daily for 14 days. Paw volume was measured on days $0,3,7,11$, and 14 [19].

\section{Statistical Analysis}

Values were expressed as mean \pm S.E.M. Statistical significance of weight or volume change was determined by ANOVA, followed by Dunnet's $t$-test; values with $\mathrm{P}<0.05$

Table 1. Anti-inflammatory Activity of BVE and BVPT in Carrageenan Induced Rat Paw Edema Model

\begin{tabular}{|c|c|c|c|c|c|c|}
\hline \multirow[b]{2}{*}{ Group } & \multirow[b]{2}{*}{ Treatment } & \multirow[t]{2}{*}{ Dose $(\mathrm{mg} / \mathbf{k g})$} & \multicolumn{4}{|c|}{ Increase in Paw Volume $(\mathrm{mL})$} \\
\hline & & & $1 \mathrm{~h}$ & $2 \mathrm{~h}$ & $3 \mathrm{~h}$ & $4 \mathrm{~h}$ \\
\hline II & Diclo & 13.5 & $\begin{array}{c}0.23 \pm 0.03 \\
(51.1)\end{array}$ & $\begin{array}{c}0.21 \pm 0.12 * \\
(70.4)\end{array}$ & $\begin{array}{c}0.18 \pm 0.12 * \\
(79.6)\end{array}$ & $\begin{array}{c}0.16 \pm 0.07 * * \\
(82.0)\end{array}$ \\
\hline IV & $\mathrm{BE}$ & 200 & $0.36 \pm 0.23(23.4)$ & $0.42 \pm 0.14(40.8)$ & $0.35 \pm 0.18(60.2)$ & $0.32 \pm 0.2(64.0)$ \\
\hline V & $\mathrm{BE}$ & 400 & $0.30 \pm 0.15(36.2)$ & $0.27 \pm 0.06^{*}(62.0)$ & $0.25 \pm 0.2 *(71.6)$ & $0.22 \pm 0.1 *(75.3)$ \\
\hline VI & BVPT & 100 & $\begin{array}{c}0.38 \pm 0.22 \\
(19.2)\end{array}$ & $\begin{array}{c}0.34 \pm 0.11 \\
(52.1)\end{array}$ & $\begin{array}{c}0.28 \pm 0.11 \\
(68.2)\end{array}$ & $\begin{array}{c}0.26 \pm 0.15^{*} \\
(70.8)\end{array}$ \\
\hline
\end{tabular}

Notes: All the result are expressed in term of Mean \pm S.E.M., $\mathrm{n}=6$ animals in each group; number in parenthesis indicates percentage inhibition in increase in paw volume. Statistical significance was determined by ANOVA, followed by Dunnet's $t$-test. * $\mathrm{p}<0.05, * * \mathrm{p}<0.01$, statistically significant. 
Table 2. Effects of BVE and BVPT on Cotton Pellets Induced Granuloma Formation in Rats

\begin{tabular}{|c|c|c|c|c|c|c|}
\hline \multirow[b]{2}{*}{ Groups } & \multirow[b]{2}{*}{ Treatment } & \multirow[b]{2}{*}{$\begin{array}{c}\text { Dose } \\
(\mathrm{mg} / \mathrm{kg})\end{array}$} & \multicolumn{2}{|c|}{ Moist Cotton Pellet } & \multicolumn{2}{|c|}{ Dried Cotton Pellet } \\
\hline & & & Weight (mg) & $\%$ inhibition & Weight (mg) & $\%$ inhibition \\
\hline I & Control & - & $210.40 \pm 11.6$ & - & $52.57 \pm 2.4$ & - \\
\hline II & Diclo & 13.5 & $93.26 \pm 5.8^{* *}$ & 55.7 & $21.02 \pm 0.5^{* *}$ & 60.0 \\
\hline III & BVE & 100 & $190 \pm 9.8$ & 9.7 & $47.78 \pm 1.6$ & 9.1 \\
\hline IV & BVE & 200 & $178.38 \pm 8.6$ & 15.2 & $45.68 \pm 2.13$ & 13.1 \\
\hline $\mathrm{V}$ & BVE & 400 & $156.72 \pm 6.3^{*}$ & 25.5 & $39.87 \pm 1.0^{*}$ & 24.2 \\
\hline VI & BVPT & 100 & $170.48 \pm 10.4$ & 19.0 & $46.43 \pm 1.3$ & 11.3 \\
\hline VII & BVPT & 200 & $132.80 \pm 8.7^{*}$ & 36.9 & $31.93 \pm 1.4 *$ & 39.3 \\
\hline VIII & BVPT & 400 & $114.63 \pm 7.8^{* *}$ & 45.5 & $24.89 \pm 0.7 * *$ & 52.7 \\
\hline
\end{tabular}

Table 3. Anti-inflammatory Activity of BVE and BVPT in Adjuvant Induced Arthritis in Rats

\begin{tabular}{|c|c|c|c|c|c|c|c|}
\hline \multirow{2}{*}{ Group } & \multirow{2}{*}{ Treatment } & \multirow{2}{*}{$\begin{array}{c}\text { Dose } \\
(\mathrm{mg} / \mathrm{kg})\end{array}$} & \multicolumn{5}{|c|}{ Increase in Paw Volume $(\mathrm{mL})$} \\
\hline & & & 0 day & 3 day & 7 day & 11 day & 14 day \\
\hline I & Control & - & $0.49 \pm 0.1$ & $0.64 \pm 0.2$ & $0.82 \pm 0.09$ & $0.98 \pm 0.12$ & $1.12 \pm 0.29$ \\
\hline II & Diclo & 13.5 & $0.44 \pm 0.08(10.2)$ & $\begin{array}{c}0.52 \pm 0.06 \\
\quad(18.8)\end{array}$ & $\begin{array}{c}0.58 \pm 0.21 \\
(29.3)\end{array}$ & $\begin{array}{l}0.45 \pm 0.24 \\
\quad(54.1)\end{array}$ & $0.33 \pm 0.1 *(70.5)$ \\
\hline III & BVE & 100 & $0.48 \pm 0.09(2.0)$ & $0.62 \pm 0.16(3.1)$ & $0.78 \pm 0.13(4.9)$ & $\begin{array}{l}0.75 \pm 0.11 \\
\quad(23.5)\end{array}$ & $0.69 \pm 0.26(38.4)$ \\
\hline IV & BVE & 200 & $0.48 \pm 0.18(2.0)$ & $0.61 \pm 0.25(4.7)$ & $\begin{array}{c}0.69 \pm 0.16 \\
(15.9)\end{array}$ & $0.67 \pm 0.3(31.6)$ & $0.58 \pm 0.15(48.2)$ \\
\hline $\mathrm{V}$ & BVE & 400 & $0.47 \pm 0.16(4.1)$ & $0.59 \pm 0.19(7.9)$ & $0.66 \pm 0.2(19.6)$ & $\begin{array}{c}0.63 \pm 0.21 \\
\quad(35.7)\end{array}$ & $0.41 \pm 0.17 *(63.4)$ \\
\hline VI & BVPT & 100 & $0.48 \pm 0.16(2.0)$ & $\begin{array}{c}0.60 \pm 0.28 \\
(6.3)\end{array}$ & $0.74 \pm 0.25(9.8)$ & $\begin{array}{l}0.70 \pm 0.32 \\
\quad(28.6)\end{array}$ & $0.62 \pm 0.14(44.6)$ \\
\hline VII & BVPT & 200 & $0.47 \pm 0.22(4.1)$ & $\begin{array}{c}0.58 \pm 0.11 \\
(9.4)\end{array}$ & $\begin{array}{c}0.68 \pm 0.14 \\
\quad(17.1)\end{array}$ & $\begin{array}{c}0.59 \pm 0.1 \\
(39.8)\end{array}$ & $0.51 \pm 0.26(54.5)$ \\
\hline VIII & BVPT & 400 & $0.46 \pm 0.17(6.1)$ & $\begin{array}{c}0.55 \pm 0.13 \\
\quad(14.1)\end{array}$ & $\begin{array}{c}0.63 \pm 0.27 \\
\quad(23.2)\end{array}$ & $\begin{array}{c}0.53 \pm 0.13 \\
(45.9)\end{array}$ & $0.39 \pm 0.05 *(65.2)$ \\
\hline
\end{tabular}

Notes: All the result are expressed in term of Mean \pm S.E.M., $\mathrm{n}=6$ animals in each group; number in parenthesis indicates percentage inhibition in increase in paw volume. Statistical significance was determined by ANOVA, followed by Dunnet's $t$-test. * $\mathrm{p}<0.05$, statistically significant.

and $\mathrm{p}<0.01$ were considered as statistically significant. GraphPad Prism version 4.0, GraphPad Software Inc., was used for statistical analysis.

\section{RESULTS AND DISCUSSION}

Carrageenan-induced rat paw edema model has been in use to evaluate anti-inflammatory activity of drugs. The carrageenan induced edema develops by mediators in three phases. The initial phase is caused by histamine release, whereas the second phase is mediated by kinin and bradykinin, and the late phase by prostaglandins $[20,21]$. Most antiinflammatory drugs are effective at the late phase of edema formation [22]. As shown in Table 1, Diclo (Diclofenac sodium $13.5 \mathrm{mg} / \mathrm{kg}$ ) showed significant inhibition of rat paw edema at $4 \mathrm{~h}(82.0 \%)$. At $400 \mathrm{mg} / \mathrm{kg}$, the paw edema inhibition following treatment with BVE and BVPT was $75.3 \%$ and $80.0 \%$ respectively. At this dose, the anti-inflammatory activity of both extracts is comparable to Diclo, and a significant reduction can be observed even $2 \mathrm{~h}$ post induction. BVPT appears to be more active (Table 1).

The anti-inflammatory effect of the extracts was further investigated by the cotton pellets induced granuloma formation in rats, which is a model for chronic inflammation. In this model granuloma formation is due to proliferation of 
inflammatory cells like macrophages, fibroblasts and neutophils $[23,24]$. Diclofenac sodium and the plant extracts (BVE and BVPT) reduced the wet cotton pellet weight (Table 2), an indication of reduction in accumulation of exudates at the inflammation site [25]. Administration of Diclo at $13.5 \mathrm{mg} / \mathrm{kg}$ resulted in $56.0 \%$ weight reduction, whereas, BVPT at 200 and $400 \mathrm{mg} / \mathrm{kg}$ reduced the weight by 37.0 and $46.0 \%$ respectively. BVE at $400 \mathrm{mg} / \mathrm{kg}$ reduced the weight of the wet cotton pellet by $26.0 \%$. As shown in Table 2, Diclo $(13.5 \mathrm{mg} / \mathrm{kg})$ showed significant $60.0 \%$ reduction of dried cotton pellet weight. Likewise both BVE $(400 \mathrm{mg} / \mathrm{kg})$, and BVPT at $200 \mathrm{mg} / \mathrm{kg}$ and $400 \mathrm{mg} / \mathrm{kg}$ showed significant reduction in the pellets weight $(24.0,39.0$ and $53.0 \%$, respectively), suggesting an anti-proliferative activity $[23,25]$.

The FCA induced arthritis was assessed by formation of rat paw edema [26, 27]. Diclo at $13.5 \mathrm{mg} / \mathrm{kg}$ significantly inhibited the edema $(71.0 \%)$ on the $14^{\text {th }}$ day of study (Table 3). The edema inhibition on this day following BVE and BVPT treatment at $400 \mathrm{mg} / \mathrm{kg}$ was 63.0 and $65.0 \%$ respectively.

\section{ACKNOWLEDGEMENTS}

Authors are thankful to Nitte Gulabi Shetty Memorial Institute of Pharmaceutical Sciences for providing the necessary facilities and infrastructure for the study. Authors are also grateful to Nitte University for the financial support.

\section{CONFLICT OF INTEREST}

None declared.

\section{ABBREVIATIONS}

$$
\begin{array}{ll}
\mathrm{LD}_{50}= & \text { Median lethal dose } \\
\mathrm{FCA}= & \text { Complete Freund's adjuvant }
\end{array}
$$

\section{REFERENCES}

[1] Seth, S.D.; Sharma, B. Medicinal plants of India. Ind. J. Med. Res., 2004, 120, 9-11.

[2] Nordstrom, C.R. Exploring pluralism- the many faces of Ayurveda. Soc. Sci. Med., 1988, 27, 479-489.

[3] Kirtikar, K.R.; Basu, B.D. Indian Medicinal Plants, Vol. II, 2nd ed.; International Book Distributors: Dehradun, India, 2006; pp. 898-900.

[4] Anonymous. The Ayurvedic Pharmacopoeia of India, Part I, Vol.1, 1st ed.; Government of India, Ministry of Health and Family Welfare, Department of Health: New Delhi, India, 1989; pp. 56-57.

[5] Bhatnagar, L.S.; Singh, V.K.; Pande, G. Medico-botanical studies on the flora of Ghatigaon forests, Gwalior, Madhya Pradesh. J. Res. Ind. Med., 1973, 8, 67-100.

[6] Mali, R.G.; Mahajan, S.G.; Mehta, A.A. Rakta Kanchan (Bauhinia variegata): Chemistry, Traditional and Medicinal uses- a review. Pharmacogn Rev, 2007, 1, 314-319.

[7] Nadkarni, A.K. Dr. K. M. Nadkarni's Indian Materia Medica, Vol. I, 2nd ed.; Popular Prakashan Pvt. Ltd.: Bombay, India, 2009; pp. $184-185$.
[8] Azevedo, C.R.; Maciel, F.M.; Silva, L.B.; Ferreira, A.T.S.; da Cunha, M.; Machado, O.L.; Fernandes, K.V.S.; Oliveira, A.E.; Xavier-Filho, J. Isolation and intracellular localization of insulin-like proteins from leaves of Bauhinia variegata. Braz. J. Med. Bio. Res., 2006, 39, 1435-1444.

[9] Mohamed, M.A.; Mammoud, M.R.; Hayen, H. Evaluation of antinociceptive and anti-inflammatory activities of a new triterpene saponin from Bauhinia variegata leaves. Zeit. Natur. C., 2009, 64, 798-808.

[10] Yadava, R.N.; Reddy, V.M. Anti-inflammatory activity of a novel flavonol glycoside from the Bauhinia variegata Linn. Nat. Prod. Res., 2003, 17, 165-169.

[11] Rajkapoor, B.; Murugesh, N.; Rama Krishna D. Cytotoxic activity of a flavanone from the stem of Bauhinia variegata Linn. Nat. Prod. Res., 2009, 23, 1384-1389.

[12] Bodakhe, S.H.; Ram, A. Hepatoprotective properties of Bauhinia variegata bark extract. Yakugaku Zasshi, 2007, 127, 1503-1507.

[13] Organization for Economic Cooperation and Development (OECD). OECD Guidelines for Testing of Chemicals. Guideline 425, Acute Oral Toxicity - Up and Down Procedure (Adopted, December 17). 2001

[14] Khode, S.; Maddi, V.; Aragade, P.; Palkar, M.; Ronad, P.K.; Mamledesai, S.; Thippeswamy, A.H.M.; Satyanarayana, D. Synthesis and pharmacological evaluation of a novel series of 5-(substituted) aryl-3-(3-coumarinyl)-1-phenyl-2-pyrazolines as novel antiinflammatory and analgesic agents. Eur. J. Med. Chem., 2009, 44, $1682-1688$.

[15] Winter, C.A.; Risley, E.A.; Nuss, G.W.; Carrageenan induced edema in hind paw of the rat as an assay for anti inflammatory drugs. Proc. Soc. Exp. Bio. Med., 1962, 111, 544-547.

[16] Harris, J.M.; Spencer, P.S.J. A modified plythesmographic apparatus for recording volume changes in rat paw. J. Pharma. Pharmacol., 1962, 14, 464-466.

[17] Suleyman, H.; Demirezer, L.O.; Kuruuzum, A.; Banoglu, Z.N.; Gocer, F.; Ozabakir, G.; Gepdiremen, A. Anti-inflammatory effect of the aqueous extract from Rumex patientia L. roots. J. Ethnopharmacol., 1991, 65, 141-148.

[18] D'Arcy, P.F.; Howard, E.M.; Muggleton, P.W.; Townsend, S.B The antiinflammatory action of griseofulvin in experimental animals. J. Pharm. Pharmacol., 1960, 12, 659-665.

[19] Newbould, B.B. Chemotheraphy of arthritis induced in rats by mycobacterial adjuvant. Br. J. Pharmacol., 1963, 21, 127-136.

Vinegar, R.; Schreiber, W.; Hugo, R. Biphasic development of carrageenan oedema in rats. J. Pharmacol. Exp.Therap., 1969, 166, 96-103.

[21] DiRosa, M.; Giroud, J.P.; Willoughby, D.A. Studies on the mediators of the acute inflammatory response induced in rats in different sites by carrageenan and turpentine. J. Pathol., 1971, 104, 15-29.

[22] Niemegeers, C.J.E.; Verbruggen, F.J.; Janssen, P.A.J. Effect of various drugs on carrageenan-induced oedema in the rat hind paw. J. Pharmacol., 1964, 16, 810-816.

[23] Swingle, K.F.; Shideman, F.E. Phases of the inflammatory response to subcutaneous implantation of a cotton pellet and their modification by certain anti-inflammatory agents. J. Pharmacol. Exp. Ther., 1972, 183, 226-234.

[24] Snedegard, G. Mediators of vascular permeability in inflammation. Prog. Appl. Microcir., 1985, 7, 96-112.

[25] Spector, W.G. The granulomatous inflammatory exudates. Int. Rev. Exp. Pathol., 1969, 8, 1-55.

[26] Ward, J.R.; Cloud, R.S. Comparitive effect of antirhematic drugs on adjuvant induced polyarthritis in rats. J. Pharmacol. Exp. Ther., 1996, 152, 116-121.

[27] Croffod, L.J.; Sano, H.; Karalis, K.; Webster, E.L.; Goldmuntz, E.A., Chrousos, G.P.; Wilder, R.L. Local secretion of corticotrophin releasing hormone in joints of lewis rat with inflammatory arthritis. J. Clin. Invest., 1992, 90, 2555-2564. 